Vol 11, Issue 11, 2018

\title{
EFFECT OF RUTIN AGAINST HIGH-FAT DIET AND ALCOHOL-INDUCED ALTERATIONS IN HEMATOLOGICAL VARIABLES OF RATS
}

\author{
HEMESHWER KUMAR CHANDRA ${ }^{1}$, GITA MISHRA ${ }^{1}$, NISHA SAHU ${ }^{1}$, SATENDRA KUMAR NIRALA ${ }^{2}$, \\ MONIKA BHADAURIA ${ }^{1 *}$
}

${ }^{1}$ Department of Zoology, Toxicology and Pharmacology Laboratory, Guru Ghasidas University, Bilaspur, Chhattisgarh, India. ${ }^{2}$ Department of Rural Technology and Social Development, Guru Ghasidas University, Bilaspur, Chhattisgarh, India. Email: bhadauria_monika@rediffmail.com

Received: 29 May 2018, Revised and Accepted: 04 July 2018

\begin{abstract}
Objectives: Alcohol abuse leads to several diseases and millions of death worldwide. High-fat diet (HFD) is major contributor of non-alcoholic liver diseases and obesity. Combined consumption of HFD and alcohol has deleterious effect on blood cells. This study was carried out to evaluate the protective effect of rutin against combined consumption of HFD and alcohol-induced hematological alterations.
\end{abstract}

Methods: HFD 30\% and ethanol 10\% were administered for 4 weeks for induction of toxicity. Rutin (10, 20, and 40 mg/kg) and 50 mg/kg dose of silymarin were administered along with HFD and alcohol for 4 weeks.

Results: Combined consumption of HFD and alcohol increased mean corpuscular volume, total leukocytes count, eosinophil and monocyte, and decreased hematocrit and platelets. Administration of rutin improved hematological variables altered by HFD and alcohol consumption.

Conclusion: The present study concluded that administration of rutin may alleviate HFD and alcohol-induced hematological alterations by scavenging free radicals generation.

Keywords: High-fat diet, Alcohol, Rutin, Red blood cell, White blood cell.

(C) 2018 The Authors. Published by Innovare Academic Sciences Pvt Ltd. This is an open access article under the CC BY license (http://creativecommons. org/licenses/by/4. 0/) DOI: http://dx.doi.org/10.22159/ajpcr.2018.v11i11.27588

\section{INTRODUCTION}

In the current century, modernization and busy lifestyle promote the consumption of fast food and alcohol which leads to several health, economic, and societal problems. Consumption of high-fat diet (HFD) is one of the most important factors of excessive accumulation of fat in liver leading to metabolic disorder. Studies on non-alcoholic fatty liver disease (NAFLD) reported in which liver hypertrophy is initiated by accumulation of fat resulting increased oxidative stress [1]. Over 3 million deaths were reported in 2012 due to alcohol consumption, corresponding to $5.9 \%$ of the global or one in every 20 deaths worldwide [2]. Intake of alcohol induces expression and activity of cytochrome P4502E1 (CYP2E1) enzyme leads to conversion of ethanol to acetaldehyde. This activity of CYP2E1 enzyme needs oxygen activation, resulting in overproduction of reactive oxygen species (ROS), for example, hydrogen peroxide, hydroxyl radical, and superoxide anion radical, elevated ROS generation, along with the exhaustion or inhibition of endogenous non-enzymatic and enzymatic antioxidant by ethanol, can lead to oxidative stress in body and subsequent tissue damage [3].

Antioxidant supplements are one of the possible strategies for maintaining redox homeostasis through directly quenching excessive ROS or defending endogenous antioxidative enzyme activities against oxidative stress [4]. Polyphenolic compounds including flavonoids and phenolic acids functions as antioxidant, antihyperglycemic, and antihypertensive agent [5]. Rutin, also known as Vitamin P, is one of the major flavonoids and presents in onions, apples, tea, and red wine. It has antiviral, antihypertensive, antioxidant [6], antibacterial, antitumor, anti-inflammatory, antidiarrheal, antiulcer, antimutagenic, vasodilator, immunomodulatory, and hepatoprotective activities $[7,8]$.

Till now, there is no scientific report on protective effect of rutin against combined consumption of HFD and alcohol-induced hematological deviations. Therefore, the present investigation was an attempt to evaluate ameliorating effect of rutin against HFD and alcohol-induced hematological abnormalities in rats.

\section{METHODS}

\section{Animals and chemical}

Female albino Wistar rats $(160 \pm 10 \mathrm{~g})$ were obtained from Defense Research and Development Establishment, Gwalior, and acclimatized in departmental animal facility under standard husbandry conditions $\left(25 \pm 2{ }^{\circ} \mathrm{C}\right.$ temperature, $60-70 \%$ relative humidity, and $12 \mathrm{~h}$ photoperiod). Rats were fed with standard diet (Pranav Agro Industries, India) and water ad libitum. Experiments were conducted in accordance with the guidelines set by the Committee for the Purpose of Control and Supervision of Experiments on Animals (CPCSEA), India, and experimental protocols were approved by the institutional animal ethics committee (994/ERe/GO/06/CPCSEA). Rutin, silymarin, and other chemicals were procured from Sigma-Aldrich, Ranbaxy, and HiMedia Laboratories Ltd., India, ERBA Diagnostics, Germany. HFD was procured from VRK Nutritional Solutions, Pune (India).

\section{Experimental design}

4 weeks duration of exposure to HFD and alcohol was selected from our previous studies to induce hepatorenal disorder (Communicated). 42 animals were divided into seven groups of six animals each as follows: Group 1 and 2 received regular diet and water. Group 1 received vehicle according to body weight and served as control. Group 2 received rutin per se ( $40 \mathrm{mg} / \mathrm{kg}$, p.o.) for 4 weeks (5 days in a week). Groups 3-7 received 30\% HFD and 10\% alcohol simultaneously and Group 3 served as experimental control. Group 4, 5,6 , and 7 were treated individually with rutin at different doses of $10 \mathrm{mg} / \mathrm{kg}, 20 \mathrm{mg} / \mathrm{kg}$, and $40 \mathrm{mg} / \mathrm{kg}$ and silymarin (50 mg/kg, p.o.) considering 5 days in a week respectively. Animals of all the groups 
were euthanized after 4 weeks of experiment; blood was collected for hematological analysis.

\section{Hematological analysis}

Red blood cell (RBC), red cell distribution width (RDW), hematocrit (HCT), mean corpuscular volume (MCV), hemoglobin, mean corpuscular hemoglobin (MCH), $\mathrm{MCH}$ concentration (MCHC), platelets, platelet distribution width (PDW), mean platelet volume (MPV), total leukocytes count (TLC), monocyte, eosinophil, and lymphocyte were done by blood analyzers manual instruction guide.

\section{Statistical analysis}

Data were expressed as mean \pm standard error of six animals used in each group. Statistical analysis was carried out using one-way analysis of variance considering significant at $5 \%$ level followed by Student's t-test considering statistically significant at $\mathrm{p} \leq 0.05$ and $\mathrm{p} \leq 0.01$ [9].

\section{RESULTS}

4 weeks combined consumption of HFD and alcohol did not cause significant alteration in RBC count and RDW. HFD and alcohol consumption significantly decreased HCT and increased MCV ( $\mathrm{p} \leq 0.05)$ as compared to control. Administration of 20 and $40 \mathrm{mg} / \mathrm{kg}$ doses of rutin and $50 \mathrm{mg} / \mathrm{kg}$ dose of silymarin improved HCT count at $5 \%$ level of significance. MPV was improved only at $40 \mathrm{mg} / \mathrm{kg}$ dose of rutin $(\mathrm{p} \leq 0.05)$ (Table 1).

Hemoglobin, MCH, and MCHC were not affected significantly after 4 weeks combined consumption of HFD and alcohol (Table 2).

Table 1: Therapeutic effect of rutin against HFD and alcohol-induced hematological alterations

\begin{tabular}{lllll}
\hline Groups & $\mathbf{R B C}\left(\mathbf{1 0}^{\mathbf{3}} / \mathbf{m m}^{\mathbf{3}}\right)$ & $\mathbf{R D W}(\mathbf{\%})$ & HCT (\%) & MCV $\left(\mu \mathbf{m}^{3}\right)$ \\
\hline Group 1 & $7.51 \pm 0.58$ & $16.6 \pm 1.58$ & $52.1 \pm 3.70$ & $33.05 \pm 2.79$ \\
Group 2 & $7.54 \pm 0.62$ & $16.7 \pm 1.58$ & $52.2 \pm 3.70$ & $33.09 \pm 2.71$ \\
Group 3 & $6.59 \pm 0.62$ & $14.8 \pm 1.33$ & $37.3 \pm 2.82^{*}$ & $43.05 \pm 2.80^{*}$ \\
Group 4 & $6.86 \pm 0.65$ & $14.9 \pm 1.36$ & $44.3 \pm 2.44$ & $38.30 \pm 3.08$ \\
Group 5 & $6.91 \pm 0.62$ & $15.1 \pm 1.04$ & $49.5 \pm 2.84^{\phi}$ & $36.10 \pm 2.92$ \\
Group 6 & $7.29 \pm 0.70$ & $15.2 \pm 1.17$ & $51.3 \pm 3.20^{\phi}$ & $35.40 \pm 2.20^{\phi}$ \\
Group 7 & $7.24 \pm 0.67$ & $15.0 \pm 1.03$ & $48.5 \pm 2.99^{\phi}$ & $37.30 \pm 2.95$ \\
ANOVA & 0.37 & 0.45 & $3.59^{\omega}$ & 1.83 \\
\hline
\end{tabular}

Data are expressed as mean \pm SE; $n=6$; Significant ANOVA at ${ }^{\omega} \mathrm{p} \leq 0.05$. For Student's t-test. Significant $P$ value HFD+alcohol versus control ${ }^{*} \mathrm{p} \leq 0.05$, and therapy versus HFD+alcohol ${ }^{\Phi} \mathrm{p} \leq 0.05$. Group 1: Control; Group 2: Rutin per se (rutin $40 \mathrm{mg} / \mathrm{kg}$ ); Group 3: HFD+alcohol; Group 4: HFD+alcohol+Rutin $10 \mathrm{mg} / \mathrm{kg}$; Group 5: HFD+alcohol+Rutin $20 \mathrm{mg} / \mathrm{kg}$; Group 6: HFD+alcohol+Rutin $40 \mathrm{mg} / \mathrm{kg}$; Group 7: HFD+alcohol+Silymarin $50 \mathrm{mg} / \mathrm{kg}$. RBC: Red blood cell, RDW: Red cell distribution width, HCT: Hematocrit, MCV: Mean corpuscular volume, HFD: High-fat diet, SE: Standard error

Table 2: Therapeutic effect of rutin against HFD and alcohol-induced hematological alterations

\begin{tabular}{llll}
\hline Groups & Hemoglobin $(\mathbf{g} / \mathbf{d l})$ & MCH $(\mathbf{p g})$ & MCHC $(\mathbf{g} / \mathbf{d l})$ \\
\hline Group 1 & $14.4 \pm 1.17$ & $19.6 \pm 1.16$ & $39.15 \pm 1.54$ \\
Group 2 & $14.1 \pm 1.29$ & $19.4 \pm 1.02$ & $39.19 \pm 2.95$ \\
Group 3 & $13.6 \pm 1.15$ & $20.6 \pm 1.55$ & $40.05 \pm 2.44$ \\
Group 4 & $13.7 \pm 1.13$ & $20.4 \pm 1.54$ & $39.10 \pm 2.79$ \\
Group 5 & $13.8 \pm 1.32$ & $20.4 \pm 1.54$ & $38.90 \pm 2.31$ \\
Group 6 & $14.0 \pm 1.27$ & $19.9 \pm 1.24$ & $38.70 \pm 2.96$ \\
Group 7 & $13.2 \pm 1.05$ & $19.6 \pm 1.13$ & $38.65 \pm 2.96$ \\
ANOVA & 0.11 & 0.14 & 0.03 \\
\hline
\end{tabular}

Data are expressed as mean \pm SE; $\mathrm{n}=6$. Group 1: Control; Group 2: Rutin per se (rutin 40 mg/kg); Group 3: HFD+alcohol; Group 4: HFD+alcohol+Rutin $10 \mathrm{mg} / \mathrm{kg}$; Group 5: HFD+alcohol+Rutin 20 mg/kg; Group 6:

HFD+alcohol+Rutin 40 mg/kg; Group 7: HFD+alcohol+Silymarin 50 mg/kg MCH: Mean corpuscular hemoglobin, MCHC: Mean corpuscular hemoglobin concentration, HFD: High-fat diet, SE: Standard error
Eosinophil, monocyte count, and TLC were significantly $(\mathrm{p} \leq 0.01)$ increased after 4 weeks combined consumption of HFD and alcohol, but lymphocytes were not affected significantly by HFD and alcohol consumption. Administration of rutin 20 and $40 \mathrm{mg} / \mathrm{kg}$ improved TLC at $(\mathrm{p} \leq 0.05 ; \mathrm{p} \leq 0.01)$, respectively. Monocytes count was decreased toward control at all the doses of rutin in a dose-dependent manner $(p \leq 0.05 ; p \leq 0.01)$. Administration of rutin improved eosinophil count at higher dose only at $1 \%$ level of significance. Positive control silymarin $50 \mathrm{mg} / \mathrm{kg}$ was also improved TLC, monocyte, and eosinophil at 5\% level and $1 \%$ level of significance, respectively (Table 3 ).

4 weeks combined consumption of HFD and alcohol did not alter PDW and MPV significantly. HFD and alcohol decreased platelets count significantly at $\mathrm{p} \leq 0.05$. The highest dose of rutin $40 \mathrm{mg} / \mathrm{kg}$ and silymarin $50 \mathrm{mg} / \mathrm{kg}$ increased platelets count significantly $(\mathrm{p} \leq 0.05$; Table 4).

\section{DISCUSSION}

Alcohol abuse is a rising epidemic in India, especially among men, and nowadays, it is becoming a major problem with young adults. The clinical manifestations of alcohol-induced hematological disorders are profoundly influenced by the patient's social and economic status and other factors such as nutritional deficiency or alcoholic cirrhosis. Most of these changes may severely affect either directly or indirectly and may cause anemia; however, a patient with extensive liver disease may develop an abnormally functioning fibrinogen or other coagulation disorders, which may initiate or exacerbate bleeding [10]. In modern century, people prefer to a sedentary lifestyle and a lack of exercise which are associated with increased prevalence of diabetes mellitus, obesity, hypertension, and hypertriglyceridemia. These are considered to be important causes of NAFLD and its more destructive form, i.e., non-alcoholic steatohepatitis $[11,12]$.

Blood is a connective tissue which consists of fluid portions or plasma that is suspended by some formed elements (erythrocytes, leukocytes, and thrombocytes). Blood provides the basic connections between the organs and cells of the body and maintains a constant cellular environment by circulating through every tissue providing nutrients to them and eliminating waste products $[13,14]$. The 4 weeks combined consumption of HFD and alcohol caused significant changes in hematological variables of animals. During the metabolism of alcohol and HFD, generation of ROS takes places leading to tissue and cells damage. Previous reports suggested that ethanol intake may lead to oxidative damage to erythrocytes and other tissues [15].

Chronic drinking of alcohol changes RBC in many aspects not only regarding changes in size of $\mathrm{RBC}$ (macrocytosis) but also even the presence of defective RBC in the blood and their production from the bone marrow [16]. As a result of these changes, anemia is a common found in alcoholics [16]. In the present finding, HFD and alcohol consumption did not alter the RBC, hemoglobin, $\mathrm{MCH}$, and $\mathrm{MCHC}$, due to low concentration of alcohol and also may be short time duration of consumption. Devi and Rajkumar reported that in hyperlipidemic condition RBC and hemoglobin were not altered significantly in rats [17].

In case of tissue damage or inflammation, the platelets stick to the lesions of the blood vessels and adhere to exposed endothelial tissues [18]. The HCT is one of the key factors influencing platelet adherence to the vessel wall, and the elevation of the HCT causes rise in platelet accumulation [19]. Reduction of platelets count is associated with thrombocytopenia. In the present study, HFD and alcohol consumption decreased platelets count and HCT. The finding is in agreement with previous reports [20-22]. Rutin administration increased platelet count and HCT, which indicate the ability of rutin to ameliorate bleeding tendencies. Previous finding showed that the rutin improved platelet count against doxorubicin [23]. The MCV estimates the average erythrocyte volume and increased MCV serves 
Table 3: Therapeutic effect of rutin against HFD and alcohol-induced alterations in blood parameters

\begin{tabular}{llll}
\hline Groups & TLC (\%) & Lymphocyte (\%) & Eosinophil (\%) \\
\hline Group 1 & $10200 \pm 748$ & $78 \pm 5.46$ & $1.5 \pm 0.11$ \\
Group 2 & $10220 \pm 819$ & $81 \pm 5.00$ & $1.6 \pm 0.08$ \\
Group 3 & $14800 \pm 938^{* *}$ & $90 \pm 6.79$ & $4.5 \pm 0.30^{* *}$ \\
Group 4 & $13050 \pm 810$ & $75 \pm 5.22$ & $4.0 \pm 0.28$ \\
Group 5 & $12300 \pm 785^{\phi}$ & $72 \pm 6.47$ & $3.8 \pm 0.26$ \\
Group 6 & $10650 \pm 611^{\phi \phi}$ & $76 \pm 6.32$ & $2.4 \pm 0.17^{\phi \phi}$ \\
Group 7 & $11200 \pm 747^{\phi}$ & $78 \pm 4.91$ & $3.0^{\phi} \pm 0.30^{\phi \phi}$ \\
ANOVA & $5.68^{\omega}$ & 0.65 & $32.7^{\omega}$ \\
\hline
\end{tabular}

Data are expressed as mean \pm SE; $n=6$; Significant ANOVA at ${ }^{\omega} \mathrm{p} \leq 0.05$. For Student's test significant $\mathrm{P}$ value HFD+alcohol versus control ${ }^{* *} \mathrm{p} \leq 0.01$, and therapy versus HFD+alcohol ${ }^{\Phi} \mathrm{p} \leq 0.05$ and ${ }^{\Phi \Phi} \mathrm{p} \leq 0.01$. Group 1: Control; Group 2: Rutin per se (rutin $40 \mathrm{mg} / \mathrm{kg}$ ); Group 3: HFD+alcohol; Group 4: HFD+alcohol+Rutin $10 \mathrm{mg} / \mathrm{kg}$; Group 5: HFD+alcohol+Rutin 20 mg/kg; Group 6: HFD+alcohol+Rutin 40 mg/kg; Group 7: HFD+alcohol+Silymarin 50 mg/kg. TLC=Total leukocytes count, HFD: High-fat diet, SE: Standard error

Table 4: Therapeutic effect of rutin against HFD and alcohol-induced alterations in blood parameters

\begin{tabular}{llll}
\hline Groups & Platelet $\left(\mathbf{1 0}^{\mathbf{3}} \mathbf{\mathbf { m m } ^ { 3 } )}\right.$ & PDW $(\mathbf{\%})$ & $\mathbf{M P V}\left(\boldsymbol{\mu \mathbf { m } ^ { 3 } )}\right.$ \\
\hline Group 1 & $951 \pm 78.25$ & $17.4 \pm 1.61$ & $5.30 \pm 0.33$ \\
Group 2 & $955 \pm 75.12$ & $17.3 \pm 1.63$ & $5.35 \pm 0.37$ \\
Group 3 & $690 \pm 39.72^{*}$ & $16.5 \pm 1.47$ & $5.70 \pm 0.38$ \\
Group 4 & $711 \pm 62.02$ & $16.6 \pm 1.42$ & $5.60 \pm 0.38$ \\
Group 5 & $732 \pm 44.77$ & $16.7 \pm 1.43$ & $5.55 \pm 0.39$ \\
Group 6 & $874 \pm 44.49^{\phi}$ & $16.8 \pm 1.49$ & $5.50 \pm 0.39$ \\
Group 7 & $819 \pm 45.91^{\phi}$ & $17.3 \pm 1.62$ & $5.45 \pm 0.37$ \\
ANOVA & $4.50^{\omega}$ & 0.07 & 0.17 \\
\hline
\end{tabular}

Data are expressed as mean \pm SE; $n=6$; Significant ANOVA at ${ }^{\omega} \mathrm{p} \leq 0.05$. For Student's test significant $P$ value HFD+alcohol versus control ${ }^{*} \mathrm{p} \leq 0.05$, and therapy versus $\mathrm{HFD}+$ alcohol ${ }^{\Phi} \mathrm{p} \leq 0.05$. Group 1: Control; Group 2: Rutin per se (rutin $40 \mathrm{mg} / \mathrm{kg}$ ); Group 3: HFD+alcohol; Group 4: HFD+alcohol+Rutin $10 \mathrm{mg} /$ kg; Group 5: HFD+alcohol+Rutin 20 mg/kg; Group 6: HFD+alcohol+Rutin 40 mg/ kg; Group 7: HFD+alcohol+Silymarin $50 \mathrm{mg} / \mathrm{kg}$. PDW: Platelet distribution width, MPV: Mean platelet volume, HFD: High-fat diet, SE: Standard error

as an indicator of macrocytosis [24]. Alcohol intoxication also led macrocytosis and thrombocytopenia by increasing MCV [25]. In the present study, combined consumption of HFD and alcohol increased MCV count which may lead to macrocytosis and thrombocytopenia. Rutin administration may reduce the chance of macrocytosis and thrombocytopenia by decreasing MCV [23].

White blood cell (WBC) counts are linked with insulin resistance, Type 2 diabetes [26], stroke, coronary artery disease [27], and diabetes micro- and macro-vascular complications [28]. Leukocytes are composed of polymorphonuclear cells such as lymphocytes and monocytes. Lymphocytes, polymorphonuclear, and mononuclear leukocytes can be activated by advanced glycation end products [29], oxidative stress [30], angiotensin II [31], and cytokines [32] in state of hyperglycemia. The present investigation showed that HFD and alcohol consumption altered TLC, monocyte, lymphocyte, and eosinophil count. Findings were in corroboration with previous studies [22,17]. Flavonoids containing bioactive compounds maintained WBC counts due to their free radical scavenging property $[23,22]$. It is reported that honey and royal jelly showed significant protective effect on hematological variables [33] because they contain several bioactive compounds. Rutin administration maintained these hematological variables might be due to their antioxidant activity [7].

\section{CONCLUSION}

The result of the present study concluded that rutin prevents deleterious changes in total WBC counts, HCT, platelet count, lymphocytes, eosinophil and monocyte in HFD, and alcohol-fed rats due to its effective free radical scavenging property. Rutin may be used as a therapeutic agent to combat blood toxicity.

\section{ACKNOWLEDGEMENT}

This work was financially supported by the DBT BioCARe Scheme (DBT/ BioCare/03/854/2010-11) of Department of Biotechnology, New Delhi, India. Department of Zoology, Guru Ghasidas Vishwavidyalaya, Bilaspur, for laboratory facilities and fellowship.

\section{AUTHORS' CONTRIBUTIONS}

The first, second, and third author carried out of the experimental part of the work and data compilation. The fourth and fifth authors guided and monitored the experimental design, as well as corrected the manuscript.

\section{CONFLICTS OF INTEREST}

The authors declare that they have no conflicts of interest on any issues.

\section{REFERENCES}

1. Jung JH, Kim HS. The inhibitory effect of black soybean on hepatic cholesterol accumulation in high cholesterol and high fat diet-induced non-alcoholic fatty liver disease. Food Chem Toxicol 2013;60:404-12

2. World Health Organization. Global Status Report on Alcohol and Health. Geneva: World Health Organization; 2014.

3. Leung TM, Nieto N. CYP2E1 and oxidant stress in alcoholic and non alcoholic fatty liver disease. J Hepatol 2013;58:395-8.

4. Ying HZ, Liu YH, Yu B, Wang ZY, Zang JN, Yu CH. Dietary Quercetin ameliorates nonalcoholic steatohepatitis induced by a high fat diet in gerbils. Food Chem Toxicol 2013;52:53-60.

5. Ushida Y, Matsui T, Tanaka M, Matsumoto K, Hosoyama H, Mitomi A, et al. Endothelium-dependent vasorelaxation effect of rutin-free tartary buckwheat extract in isolated rat thoracic aorta. J Nutr Biochem 2008; 19:700-7.

6. Korkmaz A, Kolankaya D. Protective effect of rutin on the ischemia reperfusion induced damage in rat kidney. J Surg Res 2010;164:309-15.

7. Janbaz KH, Saeed SA, Gilani AH. Protective effect of rutin on paracetamol-and $\mathrm{CCl}_{4}$-induced hepatotoxicity in rodents. Fitoterapia 2002;73:557-63.

8. Lee W, Ku SK, Bae JS. Barrier protective effects of rutin in LPSinduced inflammation in vitro and in vivo. Food Chem Toxicol 2012:50:3048-55.

9. Snedecor GW, Cochran WG. Statistical Method. $8^{\text {th }}$ ed. Ames, IA: Affiliated East-West Press; 1989. p. 217-36.

10. Yoganandh T, Mayilsamy S, Radhakrishnan S. Comparison of haematological parameters between alcoholics and non-alcoholics. Int J Res Med Sci 2017;5 Suppl 11:5041-7.

11. Das SK, Mukherjee S, Vasudevan DM. Non-alcoholic fatty liver diseases: An under recognized cause with emerging importance. Current Sci 2006;90:659-65.

12. Abozid MM, Zein H, El-Halem AA. Effect of common carp and African catfish oils on rats fed on high-fat diet. Int J Pharm Pharm Sci 2018;10 Suppl 2:96-101.

13. Ganong WF. Review of Medical Physiology. $21^{\text {st }}$ ed. New York: McGraw-Hill; 2003. p. 518.

14. Sembulingam K, Sembulingam P. Essentials of Medical Physiology. $4^{\text {th }}$ ed. New Delhi, India: Jaypee Brothers Medical Publishers; 2006. p. $47-126$. 
15. Hernandez-Munoz R, Montical-Ruiz C, Vazopen-Martiny O. Gastric mucosal cell proliferation in ethanol-induced chronic mucosal injury is related to oxidative stress and lipid peroxidation in rats. Lab Invest 2000;80:1161-9.

16. Ballard HS. The hematological complications of alcoholism. Alcohol Health Res World 1997;21:42-52.

17. Devi J, Rajkumar J. Effect of ambrex (a herbal formulation) on hematological variables in hyperlipidemic rats. Pak J Biol Sci 2014;17 Suppl 5:740-3.

18. Ogasawara F, Fusegawa H, Haruki Y, Shiraishi K, Watanabe N, Matsuzaki S, et al. Platelet activation in patients with alcoholic liver disease. Tokai J Exp Clin Med 2005;30:41-8.

19. Aarts PA, Bolhuis PA, Sakariassen KS, Heethaar RM, Sixma JJ. Red blood cell size is important for adherence of blood platelets to artery sub endothelium. Blood 1983;62:214-7.

20. Niemelä O. Serum diagnosis of alcoholic liver disease and markers of ethanol intake. In: Sherman DIN, Preedy VR, Watson RR, editors. Ethanol and Liver. Mechanisms and Management. London: Taylor and Francis; 2002. p. 411-49.

21. Levine RF, Spivak JL, Meagher RC, Sieber F. Effect of ethanol on thrombopoiesis. Br J Haematol 1986;62:345-54.

22. Mahmoud AM. Hematological alterations in diabetic rats-role of adipocytokines and effect of citrus flavonoids. EXCLI J 2013;12:647-57.

23. Parabathina RK, Muralinath E, Swamy PL, Krishna VV, Sree KS. Effects of vitamin-E, Morin, Rutin, Quercetin AGAINST doxorubicin in rabbits: A hematological study. Res J Pharm Biol Chem Sci 2011;2 Suppl 3:74-84.

24. Lindenbaum J. Hematologic complications of alcohol abuse. Semin Liver Dis 1987;7:169-81.

25. Chu YC. Hematological effect of alcohol, long-term ethanol consumption in alcoholics. Alcohol Clin Exp Res 2000;24:117-22.
26. Ohshita K, Yamane K, Hanafusa M, Mori H, Mito K, Okubo M. Elevated white blood cell count in subjects with impaired glucose tolerance. Diabetes Care 2004;27;491-6.

27. Lee CD, Folsom AR, Nieto FJ, Chambless LE, Shahar E, Wolfe DA. White blood cell count and incidence of coronary heart disease and ischemic stroke and mortality from cardiovascular disease in African-American and white men and women: Atherosclerosis risk in communities study. Am J Epidemiol 2001;154:758-64.

28. Tong PC, Lee KF, So WY, Ng MH, Chan WB, Lo MK. White blood cell count isassociated with macro and microvascular complications in Chinese patients with Type 2 diabetes. Diabetes Care 2005;27:216-22

29. Pertynska-Marczewska M, Kiriakidis S, Wait R, Beech J, Feldmann M, Paleolog EM. Advanced glycation end products upregulate angiogenic and pro-inflammatory cytokine production in human monocyte/ macrophages. Cytokine 2004;28:35-47.

30. Shurtz-Swirski R, Sela S, Herskovits AT, Shasha SM, Shapiro G, Nasser L. Involvement of peripheral polymorphonuclear leukocytes in oxidative stress and inflammation in Type 2 diabetic patients. Diabetes Care 2004;24:104-10.

31. Lee P, Peng H, Gelbart T, Beutler E. TheIL-6- and lipopolysaccharideinduced transcription of hepcidin in HFE-, transferrin receptor 2-, and beta 2 microglobulin deficient hepatocytes. Proc Natl Acad Sci U S A 2004;101:9263-5.

32. Scherberich JE. Proinflammatory blood monocytes: Main effector and target cells in systemic and renal disease; Background and therapeutic implications. Int J Clin Pharmacol Ther 2003;41:459-64.

33. Bhalchandra W, Alqadhi YA, Ninawe AS. Ameliorative role of bee honey and royal jelly against cisplatin induced alteration in hematological parameters in male wister albino rat. Int J Pharm Pharm Sci 2018;10 Suppl 4:110-4 